\title{
Development of Green Building Materials
}

\author{
Jing $\mathrm{Wu}^{1}$ \\ ${ }^{1}$ Urban Construction Department, Hubei Engineering University, Xiaogan, China
}

Key words: green building materials; development; environmental protection

Abstract. Green building materials is one of the specific embodiment of the sustainable development strategy in the field of architecture. Because of the differences in geographical, concepts and technology, the countries' understanding of green building materials and the application are different, and the power to focus on is also different. At present, modern green building material development situation and development speed are presented good trend, indicated that it will have very good prospects for development. More and more new and high quality green building materials will be developed and used.

\section{Introduction}

Green building materials refers to the health, environmental protection, safety of building materials, the international is also known as health building materials, green building materials or Eco building materials. In other words, green building materials refers to the adoption of cleaner production technology, occupies less natural resources and energy, use of urban solid or liquid waste to produce the materials which is non-toxic, and no-pollution, and which is conducive to human health. The most basic function of green building materials is to maintain human health and protect the environment. Green building materials is not a single species, but on the evaluation of the character of the building materials health, environmental protection, safety.

\section{Modern Green Concrete Materials}

When the concrete is the main building material of modern architecture, it is very important to develop green concrete material for green building.

High performance concrete is a new type of high technology of concrete, to greatly improve the performance of conventional concrete based on, with characteristics such as excellent durability, applicability, work, all kinds of mechanical properties, volume stability and economic rationality. High performance concrete in addition to the use of high-quality cement, water, aggregate, must also be the low water binder ratio, adding a sufficient number of fine mineral admixture and high efficient additives, using modern concrete technology, high-quality raw materials, made by the proper quality control.

Now, a large number of studies have indicated that the waste concrete can be used as recycled concrete aggregate, but also can replace some of the high quality limestone to produce cement. The waste concrete washing, crushing, grading, and according to a certain proportion to obtain the aggregate called recycled aggregate, recycled aggregate concrete as a part or all of the aggregate allocation become recycled concrete. Experimental results show that the recycled concrete compressive strength can meet the design requirements and other mechanical properties and 
durability index is similar to ordinary concrete, and in the need of water more than the ordinary concrete.

Aerated concrete is with quartz sand based, with cement and lime as cementitious material, gypsum as hardening agent, aluminium as foaming agent, formed after high-temperature and highpressure curing pupil like material.

Planting concrete have continuous gap, the gap part using special technology of inorganic filling soil, fertilizer and seed culture mixed growth base material, after construction, seed germination and growth need moisture, except by saving in the growth of base material in the rain, can also absorb planting concrete below the base planting concrete, do not need more water. This not only achieved a green, but also to prevent the surface of the structure is contaminated and erosion, wood became the bright spot of modern building materials, with the progress of technology has been a lot of new use form.

\section{Wood}

Use of advanced dyeing technology, so that the color of the original trees in the infiltration of wood tissue, to form color wood. It can be divided into two kinds, the first is natural colored wood. That is, in the various stages of wood growth, to the root of the tree or the trunk of the tree to the infusion of harmless water, soluble nutrient solution. Color along the trees and is absorbed, the inner catheter transmission coloring, and form the color wood. The other one is acquired colored wood. That is, select the rich texture of the wood slices, the first step is color processing, and then give the right color. Color wood is suitable for making furniture, ceiling, wall and other large areas of decoration.

With a chemical solution containing barium ions to soak the wood, so that the barium ion diffusion, penetration into the wood tissues and cells, the use of a certain process, the wood into porcelain wood. Porcelain wood is hydrophobic and stable, and with excellent flame retardant properties. Through the jet flame test, not out of the flames, almost no smoke, only low carbonation. This kind of super flame retardant wood is suitable for hall furniture and decoration, which is suitable for the interior of the vehicle, especially in the large public entertainment place.

The ethylene resin is injected into the wood to form a plastic wood. Plastic wood has a very strong compression, bending, shear strength, greatly reducing the crack and other defects, has a strong wear resistance and hardness. Plastic wood will be widely used in floor decoration works.

The expansion rate of the hydrophobic wood in the wet air is only half of the ordinary wood, and the water absorption is only $1 / 5$ of the ordinary wood. The principle of hydrophobic material is that the hydrophobia active hydroxide groups of wood can be converted into hydrophobic acetylene groups.

\section{Thermal Insulation Materials}

Heat preservation material can be divided into inner and outer heat preservation material according to the different parts of the building. According to the different state of the different can be divided into plate, slurry. The main properties of thermal insulation materials are: thermal conductivity, 
apparent density, compressive strength, size change rate, water absorption, water vapor permeability coefficient, bond strength and oxygen index. Plate heat insulation materials can be used for internal and external insulation works. With the characteristics of its shape, it has the advantages of simple use, and can ensure the thickness of the insulation layer, the performance is relatively stable. Excellent plate heat insulation material include foam polystyrene board, extruded polystyrene board, rock wool board, glass wool board. Pulp body heat insulation material is mainly used for external wall heat preservation, also used for wall insulation and wall insulation. There are two types of slurry material, which is mainly based on the cementitious material and the dry type of water evaporation. Its main ingredients are made of polystyrene, mineral fiber, silicate based on a variety of materials, through a certain production process to meet the light insulation materials.

\section{Waterproof Materials}

Modern green building waterproof material not only has the basic waterproof function, but also has other functions such as heat preservation, decontamination, and in the process of the production of the environment has little effect.

Polymer cement waterproof coating with cement and acrylic acid as the main raw material, adding other additives to make a two-component water-based building waterproof coating. Two groups in the field of mixing into uniform, fine slurry, brushing or spraying on the surface of the matrix, the formation of flexible, high strength waterproof coating. The coating has both high strength cement materials, easy and moist surface adhesion properties, and characteristics of both polymer film elasticity, waterproof good. In particular, water as a carrier to overcome the asphalt, tar, organic solvent based waterproof material has caused environmental pollution. It is a non-toxic harmless, wet work, construction of a simple new type of environmentally friendly waterproof material and is not only suitable for all kinds of waterproof engineering, but also can be used to repair, interface treatment, concrete protection, decoration, structural sealing and other projects.

Capillary crystalline waterproof material is refers to the penetration of materials containing the active chemical substances to the inner of concrete, in the concrete to form insoluble in water crystals and block the pores, thus forming a dense concrete and waterproof material with excellent waterproof performance.

Impervious plastic mending agent is a kind of new building chemical paint which can quickly prevent leakage of houses. Impervious plastic repair agent use of waste plastic woven bag, plastic film, foam, etc. as raw materials, and then with a reasonable plasticizer, curing agent, then use of low pressure cold soluble reaction to produce. It has the characteristics of quick drying, fast drying, good smoothness, sealing, bonding and so on. Its production process is not only less than the equipment investment, save energy, and completely eliminate the pollution of waste plastics on the environment.

Polyethylene composite waterproofing membrane using high pressure method to produce low density linear polyethylene resin as the main material, its two composite chemical fiber non-woven fabric, and through a special process to produce. Polyethylene composite waterproofing membrane

has better comprehensive technical performance, such as high tensile strength, resistance to 
penetration, low temperature flexibility good air tightness, etc.. And it has the abilities to resist acid and corrosion. Service life is long.It is a new material to build or rebuild a house.Conclusion

Green building materials is one of the specific embodiment of the sustainable development strategy in the field of architecture. Because of the differences in geographical, concepts and technology, the countries' understanding of green building materials and the application are different, and the power to focus on is also different. At present, modern green building material development situation and development speed are presented good trend, indicated that it will have very good prospects for development. More and more new and high quality green building materials will be developed and used.

\section{References}

[1] Jin Lei, Architectural science and culture (1999)

[2] Yang Jing, Building materials and human settlement (2002)

[3] Luo Deqi, Construction of healthy human settlement, Journal of Architecture 4 (2004) 35-38. 